\title{
The Effect of Hostile Environment and Harassment on Employees' Turnover Intentions, Absenteeism and Employees' Performance: A Case Study of Tertiary Hospitals of Khyber Pakhtunkhwa, Pakistan
}

\author{
WAQAS AHMAD \\ Junior Clerk, Nowshera Medical College, Nowshera \\ Ahmad.waqas22@gmail.com \\ HAJI MUHAMMAD ZUBAIR \\ Deputy Director, Burns and Trauma Center Hayatabad, Peshawar \\ Haji7864u@gmail.com \\ SAYYAM \\ Research Assistant, Institute of Business Studies \& Leadership \\ Abdul Wali Khan University, Mardan \\ sayyam@awkum.edu.pk
}

\begin{abstract}
The hostile environment and harassment in the workplace are a major problem in hospitals and have enormous negative consequences. The motive for this study is to look at the impacts of the hostile environment and, particularly, workplace harassment on performance, absenteeism and employee turnover intentions. The target population of the study was employees who worked in different KPK hospitals. The non-random snowball techniqueused to gather information from 255 respondents utilizing the questionnaire. The findings of this study show a clear picture about the relationships between study variables that the hostile environment and harassment in the workplace has a positive impact on employee turnover, absenteeism and negative impact on the performance of employees. Employees who work in hospitals need a safe and healthy environment for their commitment to duties and responsibilities. The numbers, facts and findings of this study prove that if hospitals do not provide a safe and healthy environment for employees, there must be negative consequences on the attitude or level of performance. As employees' working in hospitals directly related to patients, if they are harassed and tense and environment is not supporting them that would leads to the general failure of hospitals. Hospital management must take serious action on such a hostile environment and whatever the circumstances, they must provide the safe and healthy environment for their employees as their basic requirement to work more positively and effectively.
\end{abstract}

Keywords: Hostile Environment, Work Place Harassment, Employees' Absenteeism, Employees' Turnover Intentions, Employee' Performance

\section{Introduction}

Threatening climate is notable issue in the work environment, truth be told, cases multiplied in ongoing decades in connection to badgering and this issue has much effect on different aspects of employees. The hostile environment disturbs the routine activities and the domestic life of the employees(Turnbull, Lawry, Lowenberg, \& Richards, 2016). A ceaseless endeavor to anguish, torment, wear off, treat remorselessly, startled, dreadful 
and tentative someone else is badgering. Working environment harassing is a persevering misconduct in the work place that may cause physical or enthusiastic injury. One can characterize work environment tormenting as the all-inclusive and lasting introduction to an unseemly conduct from colleague(Webber, 2019). Hostile environment is that substantial service or monetary damage, for example, release, downgrade, undesirable and unsuitable conduct, or an adjustment in business, require not happen for the unfortunate casualty to make a grievance of unfriendly provocation to the workplace. Provocation that makes an antagonistic or harsh workplace may incorporate the conduct of bosses, associates, and non-representatives in the work environment or business related site. What's more, the casualty of provocation require not really have been the immediate focus of the conduct.The lewd behavior looked by female workers is undesirable quiet remarks about the physical, gaze and any exasperating unobtrusiveness about the conduct and think about the female group as a shabby ware (Walker, 2018). Harassment can be defined as the unethical behavior it contains and repeatedly. There are two kinds of unlawful provocation: compensation and hostile atmosphere(Maryati Binti Omar, 2008).Harassment in the workplace negatively affects work performance and indirectly organizational performance (Osman, Shariff, \& Lajin, 2016).Employee performance is essential to the organization as it is a way of assessing an organization's success, profit, market share, earnings, growth rate, and quality of service, competence, and productivity. There are many ways to increase employee performance. He also found that employee performance increases organizational performance indirectly. Employee performance is the way employeesachieve organizational goals and gain competitive advantage in the marketplace(Osman et al., 2016). Discriminatory Harassment: Here is this type of harassment that the harasser harasses the victim on the basis of a class, which may be racial, gender, religious ( Ismail, M. 2019). Personal Harassment: Can be define as personal attack on anyone, including offensive jokes, disheartening behavior, humiliation and other negative comments(Lee, Kim, Shin, \& Lee, 2016). Physical harassment: This type of harassment is more common in health workers, peace officers, social service workers, teachers, educators, retail staff and public transport drivers where the harasser has physically attacked the victim who is beating, pushing, grabbing, kicking etc and what is more commonly known as workplace violence(Aytac, Dursun, \& Akalp, 2016b). Psychological harassment: Psychological harassment defines as detrimental to the psychological well-being of the victim, where they also have an impact on their physical health, social life and professional life.

Turnover is the voluntary or involuntary departure of the organization. Employee leaves the organization, and if an organization plans to remove employees from the position (Atef, El Leithy, \& Al-Kalyaubi, 2017).Employee turnover is when the employee is completely detached from an organization and includes dismissal, layoffs, and layoffs. Employee turnover is extremely detrimental to an organization's profitability and productivity (Bryant, 2017). Absenteeism of the official: According to the research, the previous absence predicts future absence. Absence and turnover are inter-correlated; employees leaving a job before absence indicate possibility of turnover. The previous absence is related to intentions of rotation (Bryant, 2017). Employees' performance is the performance of the description of the employee's job, the performance of the employees is the completion of their job description and responsibilities accordingly(Kaare \& Otto, 2015). The aim for this exploration is to explore the threatening condition and badgering in the work environment and its impactson the 
intentions of employee turnover, employee absenteeism and employee performance in tertiary hospitals in the context of Pakistani culture.

\subsection{Problem Statement}

Harassment is an unwanted verbal, nonverbal and physical conduct that creates a hostile environment that has the reason or impact of disregarding the dignityof the employee and making a scary, unfriendly, corrupting, embarrassing hostile condition, sexual harassment, spreading like malignant cancers in workplaces that also affect the employee's performance and force employees to abstain and the intention to turnover.It has seen as a standout amongst the most troublesome and intense subject matters that businesses, representatives and HR experts confront today. Indeed, no calling or occupation exempts from this issue. Inappropriate behavior goes a long ways past the social setting, instructive dimension, age cluster or ethnicity. It contacts all layers of the populace, no matter what (Jung \& Yoon, 2018).

\subsection{Objectives of the Study}

Objectives of the study as under

- To ascertain the employee's perception about hostile environment \&harassment at workplace and their effects on employee's turnover intention

- To determine the hostile environment \&harassment at workplace and their influence on employee's absenteeism

- To determine the hostile environment andharassment at workplace and their influence on employee's performance

\subsection{Significance of Study}

The intention of this exploration is to investigate the employees' turnover intentions, absenteeism and performance of tertiary hospitals workers. The investigation will give the advantages to the equallyworkers and bosses. It will benefit to the workers as in every representative will give a chance to express their individual recognitions. The administration will get alsoadvantage by the exploration as well, as the investigation will be available to them with proposals from the respondents. It will likewise serve to make them mindful of what their workers might experience. The investigation will subsequently help administration with their endeavors and attempts toward administration of the staff.

\section{Literature Review}

Working environment provocation additionally known by main terms, "Mobbing", "work environment tormenting", "work environment abuse", "work environment animosity", "work environment attack" and "working environment misuse" are on the whole either synonymous or have a place with the class of working environment provocation. Working environment badgering incorporates diverse sorts of segregation and demonstrations of infringement that are not bound to one explicit gathering. The wide-running kinds of work environment provocation can be approximately order into enthusiastic and physical maltreatment. These types of working environment badgering target different gatherings, including women, racial minorities, gay people, individuals with incapacities and migrants(Barakat, Tag-eldeen, Barakat, \& Investigating, 2018).The hostile environment occurs when verbal and non-verbal or physical contact aimed at the harasser, and the intentions are to disrupt and constrain the workersjobexecution, creating a hostile, daunting, and unpleasantexertionatmosphere. Today, organizations face so many internal and external problems, challenges and threats. The enhancing effect of these circumstances lead toward the development of the scary business circumstance, particularized and determined by methods for a progression of negative 
practices, for example, absence of security, cluttered work, family and social relations, work environment provocation, business related pressure and stress, state of mind authoritarian by administration. In previous studies, he described anxiety for increased hostile behavior in the workplace, such as desecration of peers, conflicts, and violence. Deception, antipathy and bitterness clear in various forms such as rude behavior, physical indignation, cursing, imprecation, humiliation, shouting, threats that all of these problems create a hostile environment in the workplace that negatively affect employee performance and force employees to change of intention and absenteeism (Abbas et al., 2017).

Sexual harassment is an undesired and unwanted sexual conduct that leads to a hostile work environment (Omar, 2008). Lewd behavior incorporates an extensive variety of practices, from gross looks and jokes to embarrassing remarks dependent on sex generalizations, to rape and different demonstrations of physical brutality. In spite of the fact that the legitimate definition shifts by nation, it comprehended to allude to lead identified with unsatisfied and absurd sex. A wide definition characterizes lewd behavior as "any unwelcome lewd gestures, demands for sexual favors, verbal or physical direct or signals of a sexual sort, or whatever other sexual conduct that may sensibly be normal or might be seen as hostile or mortification to another. Such provocation might be, however not really, in a way that meddles with work, is a state of business or makes a scary, unfriendly or hostile workplace"(Elçi, Erdilek, Alpkan, \& Şener, 2014). Employee turnover is a big challenge for today's organizations. How representatives are perceived as critical authoritative resources; the hierarchical expenses acquired because of the way that representatives leave their employments and the ensuing enlisting of substitute staff, preparing for new contracts, and general organization expenses can be colossal as far as close to home, work unit, and hierarchical rearrangements(Merkin\& Shah, 2014). Along these lines, representative turnover is a noteworthy danger to associations, which requires a full clarification of their effects. Willful revolution characterized as the procedure by which a representative deliberately and intentionally closes participation to the association (Bluedon, 1978).The fulfillment in crafted by the laborers is an essential parameter that affects the profitability and the nature of the work. This intricate wonder is a state of mind towards crafted by somebody who has an effect on inspiration, as well as on profession, wellbeing and associations with colleagues(Ugwa, Muhammad, \& Ugwa, 2014). Fulfillment in crafted by wellbeing experts majorly affects the quality, adequacy and proficiency of work and, in the meantime, on human services costs. Notwithstanding its significance for patients and the wellbeing framework all in all, the expert fulfillment of wellbeing experts is straightforwardly identified with the nonattendance of work, human relations and work association (Dieleman \& Harnmeijer, 2006).

The employee's performance defined as the quality of work and the achievement of determined goals, to achieve the standard line, workplace violence that is the cause of the hostile environment adversely affects the performance and quality of the employee's work. As per the overview results, the greater part of network wellbeing specialists confronted work environment viciousness and adversely influenced work execution (Lin et al., 2015). Harassment practices are increasing in the day-to-day organization when in a mobbing organization activities disrupt and soften spoil activities, and employees try to find another opportunity elsewhere and seek to escape from the current workplace. In the last organization, lose your potential employees, which increase the organization's performance and morale. Behavior and the environment in the workplace dishearten and discourage employees from organizing. Bullying reduces the level of courage; 
enthusiasm, motivation and enthusiasm of an employee's work(Wang, Bowling, \& Kwan, 2018). Absenteeism is a churning issue such as turnover, which organizations are facing and suffering greatly and that is disrupting and hampering organizational activities. Varied types of absenteeism such as organizationally justified absence and not excused. Absences excuses are funeral leave, injuries, accidents and personal illness. Unexcused absence is the occurrence when employees do not want to attend the workplace due to intentionally such as hostile / toxic workplace, bullying, bullying and harassment(Celik \& Oz, 2011). Bullying in the workplace of employers and peers is one of the most influential factors, affecting employee performance, job satisfaction and forcing employees to change their intent. Provocation in the working environment is an unscrupulous problem as well includes workplace harassment and abuse in the workplace. Employees always want a healthy environment in the workplace. Hostile, mobbing, harassment, bullying and unethical acts affect organizational results and productivity. These results contain the employee's morale, performance, and employee turnover intent. Those employees who have harassed or suffered from bullying in the workplace are not interested in performing their duties or participating in the organization's decision-making strategies. Bullying in the workplace defined as "Consecutive and continuously incorrect conduct of an individual or group of employees to create a hostile environment in the workplace that affects the health of the employee. It also contains abusive behavior, which includes screams, humiliations, threats, interference in personal life and sabotage that restrain employees from completing their tasks(Tag-Eldeen et al., 2017).

\subsection{Hypotheses}

$\mathrm{H}_{1}$ : There is a positive relationship between hostile environment and employees turnover intentions.

$\mathrm{H}_{2}$ : There is a positive relationship between hostile environment and employee's absenteeism.

$\mathrm{H}_{3}$ : There is a negative relationship between hostile environment and employee's performance.

\subsection{Conceptual Framework}

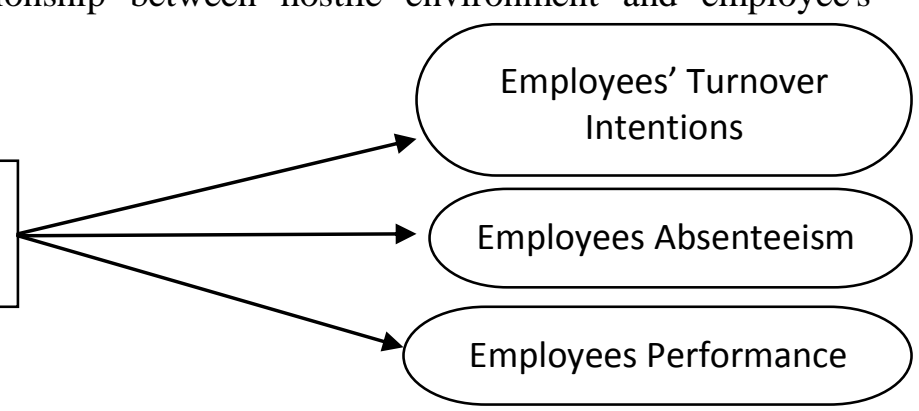

Figure 2.1 Conceptual Framework

\section{Research Methodology}

Hostile Environment \&

Harassment at Workplace

This research will aim to check the impact of the hostile environment and its effect on the intentions of employee turnover, employee absenteeism and employee performance. For this purpose, the data willcollect in Pakistan's Khyber Pakhtunkhwa tertiary hospitals.

\subsection{Population}

Targeted Population is the employees working in tertiary hospitals of Khyber Pakhtunkhwa Pakistan.

\subsection{Sample Size}

This sample size will be non-randomly selected by using snow ball sampling technique from employees working in five tertiary hospitals (HMC, KTH, LRH, QHAMC, DHQ 
Nowshera) of District Peshawar and District Nowshera, , Sample size is 255 respondents (calculated by Yamane formula 1967).

\subsection{Sampling Design}

The statistician Tara Yamane formulated the Taro Yamane method for sample size calculation in 1967 to determine the sample size.

$\mathrm{n}=\mathrm{N} /\left(1+\mathrm{N} / \mathrm{e}^{2}\right)$ :

Where:

$\mathrm{n}=$ Signifies the sample size

$\mathrm{N}=$ Signifies the population under study

$\mathrm{e}=$ signifies the margin error (it could be $0.10,0.05$ or 0.01 )

Snowball sampling technique will used for gathering data. This sampling technique helps to recognize the despondencein accordance with the study amount\& would help in collectinginformation.

\subsection{Source of Data}

Generally, the examination had essential information sources. The essential information gathered from the reactions spoke to the members in an example from utilizing the survey quantitatively estimated on a five-point Likert scale. Secondary data used as literature review previously worked on the topic by different authors in different contexts or cultures.

\subsection{Construct Reliability and Validity}

Table 1: Construct Reliability and Validity

\begin{tabular}{lcccc}
\hline $\begin{array}{l}\text { Construct Reliability and } \\
\text { Validity }\end{array}$ & $\begin{array}{c}\text { Cronbach's } \\
\text { Alpha }\end{array}$ & rho_A & $\begin{array}{c}\text { Composite } \\
\text { Reliability }\end{array}$ & $\begin{array}{c}\text { Average } \\
\text { Variance } \\
\text { Extracted } \\
\text { (AVE) }\end{array}$ \\
\hline Employees Absenteeism & 0.533 & 0.735 & 0.715 & 0.501 \\
Employees Performance & 0.673 & 0.312 & 0.689 & 0.392 \\
Employees Turnover Intention & 0.810 & 0.809 & 0.869 & 0.571 \\
Hostile Environment \& & 0.913 & 0.926 & 0.923 & 0.296 \\
Harassment at Workplace & & & & \\
\hline
\end{tabular}

In above table of construct reliability and validity the Cronbach's alpha for employees absenteeism (0.533) and employees performance (0.673) their values are little less than required value for reliability. Employee's turnover intentions (0.810) and hostile environment \& harassment at workplace (0.913) are surely enough in criteria for reliable instrument. In composite reliability, the employees performance has little low value as compare to others variables in the study. Rest three variables are in acceptable range of reliability.

\subsection{Econometrics Model:}

$\mathrm{Y}=\alpha+\beta_{1}+\beta_{2}+\beta_{3}+\mu$

ETI $=\alpha+\beta_{(\mathrm{HE})}+\mu$

EA $\quad=\alpha+\beta_{(\mathrm{HE})}+\mu$

$\mathrm{EP} \quad=\alpha+\beta_{(\mathrm{HE})}+\mu$

HEWPH= Hostile Environment Workplace Harassment (Independent Variable)

ETI = Employee's Turnover Intentions (Dependent Variable)

EA = Employee's Absenteeism (Dependent Variable) 
$\mathrm{EP}=$ Employee's Performance

(Dependent Variable)

The Independent Variable

Hostile Environment and Harassment at workplace

The Dependent Variables

Employee's turnover intentions

Employee's absenteeism

Employee's performance

\section{Results}

\subsection{Demographics Information}

Table 2: Demographic Information

\begin{tabular}{|c|c|c|c|}
\hline & Frequency & Percentage & $\begin{array}{l}\text { Cumulative } \\
\text { Percentage }\end{array}$ \\
\hline \multicolumn{4}{|l|}{ Gender } \\
\hline Male & 116 & 45.5 & 45.5 \\
\hline Female & 139 & 54.5 & 100 \\
\hline Total & 255 & 100 & \\
\hline \multicolumn{4}{|l|}{ Veil } \\
\hline Yes & 44 & 32.9 & 32.9 \\
\hline No & 93 & 67.1 & 100 \\
\hline Total & 255 & 100 & \\
\hline \multicolumn{4}{|l|}{ Age } \\
\hline $21-30$ & 152 & 59.6 & 59.6 \\
\hline $31-40$ & 83 & 32.5 & 92.2 \\
\hline $41-50$ & 20 & 7.8 & 100 \\
\hline Total & 255 & 100 & \\
\hline \multicolumn{4}{|l|}{$\begin{array}{l}\text { Marital } \\
\text { status }\end{array}$} \\
\hline Married & 120 & 47.1 & 47.1 \\
\hline Unmarried & 135 & 52.9 & 100 \\
\hline Total & 255 & 100 & \\
\hline \multicolumn{4}{|l|}{ Designation } \\
\hline Doctor & 51 & 20 & 20 \\
\hline Nurse & 112 & 43.9 & 63.9 \\
\hline Other & 92 & 36.1 & 100 \\
\hline Total & 255 & 100 & \\
\hline
\end{tabular}

From the above table and pie chart gender distribution of the sample, population or respondents are as Male $45.5 \%$ and Female showing 54.5\% of the total respondents that shows the majority of the gender group also. The table showing the percentage of responses from female respondents in sample population that whether they do veil or not, so $67 \%$ relied as No and $33 \%$ respond as Yes that shows most of female respondents not giving much importance to veil. The respondents asked about their age groups $7.8 \%$ (20 in numbers). Related to the age range of $41-50,32.5 \%$ respondents related to particular age range of $31-40$, which is 83 respondents in numbers, and majority of 
respondents related to 21-30 years age group that shows that most of respondents are in early career beginning or just start up, young and energetic. The table demonstrates the conjugal status of the respondents 53\% are married both male and female and $47 \%$ of total respondents are unmarried. The table representing the Designation of the respondents working in different hospitals of the Khyber Pakhtukhwa, 20\% of the respondents are the Doctors, $44 \%$ respondents related to the nursing field whose are definitely females and $36 \%$ respondents related to the other departments and particular jobs those are mostly with admin department and security.

\subsection{Correlation Analysis of Study Variables}

\section{Table 3: Correlation}

\begin{tabular}{|c|c|c|c|c|c|c|c|c|c|c|}
\hline & & Gender & Veil & Age & $\begin{array}{c}\text { Marital } \\
\text { status }\end{array}$ & Designation & ETI & EA & EP & EHWPH \\
\hline \multirow{3}{*}{ Gender } & Pearson Correlation & 1 & & & & & & & & \\
\hline & Sig. (2-tailed) & & & & & & & & & \\
\hline & $\mathrm{N}$ & 255 & & & & & & & & \\
\hline \multirow{3}{*}{ Veil } & Pearson Correlation & $-.640^{* *}$ & 1 & & & & & & & \\
\hline & Sig. (2-tailed) & .000 & & & & & & & & \\
\hline & $\mathrm{N}$ & 255 & 255 & & & & & & & \\
\hline \multirow{3}{*}{ Age } & Pearson Correlation & .049 & .085 & 1 & & & & & & \\
\hline & Sig. (2-tailed) & .438 & .175 & & & & & & & \\
\hline & $\mathrm{N}$ & 255 & 255 & 255 & & & & & & \\
\hline \multirow{3}{*}{$\begin{array}{l}\text { Marital } \\
\text { status }\end{array}$} & Pearson Correlation & -.072 & .041 & $-.248^{* *}$ & 1 & & & & & \\
\hline & Sig. (2-tailed) & .249 & .511 & .000 & & & & & & \\
\hline & $\mathrm{N}$ & 255 & 255 & 255 & 255 & & & & & \\
\hline \multirow{3}{*}{ Designation } & Pearson Correlation & -.025 & .028 & $-.141^{*}$ & -.104 & 1 & & & & \\
\hline & Sig. (2-tailed) & .688 & .651 & .024 & .097 & & & & & \\
\hline & $\mathrm{N}$ & 255 & 255 & 255 & 255 & 255 & & & & \\
\hline \multirow{3}{*}{ ETI } & Pearson Correlation & $-.139^{*}$ & .105 & $-.193^{* *}$ & -.020 & .085 & 1 & & & \\
\hline & Sig. (2-tailed) & .026 & .093 & .002 & .754 & .174 & & & & \\
\hline & $\mathrm{N}$ & 255 & 255 & 255 & 255 & 255 & 255 & & & \\
\hline \multirow{3}{*}{ EA } & Pearson Correlation & $.131^{*}$ & $.06 \overline{6}$ & .080 & -.085 & $-.125^{*}$ & $.490^{* *}$ & 1 & & \\
\hline & Sig. (2-tailed) & .037 & .292 & .205 & .175 & .045 & .000 & & & \\
\hline & $\mathrm{N}$ & 255 & 255 & 255 & 255 & 255 & 255 & 255 & & \\
\hline \multirow{3}{*}{ EP } & Pearson Correlation & -.071 & .053 & .096 & -.022 & $-.180^{* *}$ & -.075 & -.055 & 1 & \\
\hline & Sig. (2-tailed) & .258 & .402 & .126 & .724 & .004 & .236 & .383 & & \\
\hline & $\mathrm{N}$ & 255 & 255 & 255 & 255 & 255 & 255 & 255 & 255 & \\
\hline \multirow{3}{*}{ HEWPH } & Pearson Correlation & $.228^{* *}$ & $\begin{array}{r}- \\
.008\end{array}$ & .041 & -.117 & $-.127^{*}$ & $.393^{* *}$ & $.476^{* *}$ & $.143^{*}$ & 1 \\
\hline & Sig. (2-tailed) & .000 & .904 & .514 & .063 & .042 & .000 & .000 & .022 & \\
\hline & $\mathrm{N}$ & 255 & 255 & 255 & 255 & 255 & 255 & 255 & 255 & 255 \\
\hline
\end{tabular}


Correlation analysis shows the strength and direction of relationship between independent and dependent variables.Hostile environment and workplace harassment (independent variable) has $(\mathrm{r}=.228)$ has positive and low association with Gender of the respondents.Hostile environment and workplace harassment (independent variable) has( $\mathrm{r}$ $=-.008)$ has negative and very low relationship with veil of the respondents. Hostile environment and workplace harassment (independent variable) has $(\mathrm{r}=.041)$ positive but very low relationship with Age of the respondents in the study. Hostile environment and workplace harassment (independent variable) has $(\mathrm{r}=-.117)$ negative and low kind of relationship in the study with marital status of the respondents.Hostile environment and workplace harassment (independent variable) has $(\mathrm{r}=-.127)$ negative and low relationship in strength with designations of the respondents in the study. Hostile environment and workplace harassment(independent variable) has $(r=.393)$ positive and moderate kind of relationship with employees turnover intention this shows moderate relationship between two variables in study and their positive relationship also that means if there is increase in one variable there will be definite increase in other variable also.Hostile environment and workplace harassment(independent variable) has $(r=.476)$ positive and moderate relationship with Employees absenteeism, increase in workplace harassment and hostile environment will definite increase in the absenteeism of employees that shows the positive relationship direction between two variables.Hostile environment and workplace harassment(independent variable) has $(\mathrm{r}=-.143)$ Negative and low relationship with Employees performance this shows that if there is increase in workplace harassment and hostile environment there will be decrease in the employees performance because the relationship direction is negative. According to above correlation analysis there are some positive and negative relationships between independent variables(Hostile environment and workplace harassment) and dependent variables (employees turnover intentions ,employee's absenteeism and employees performance) .these correlations are initials evidences for further study the regression analysis carried out for knowing exact impact of the independent variables on dependent variables.

Table 4: Regression Analysis to check the effect of Hostile Environment and Workplace Place Harassment on Employees' Turnover Intentions

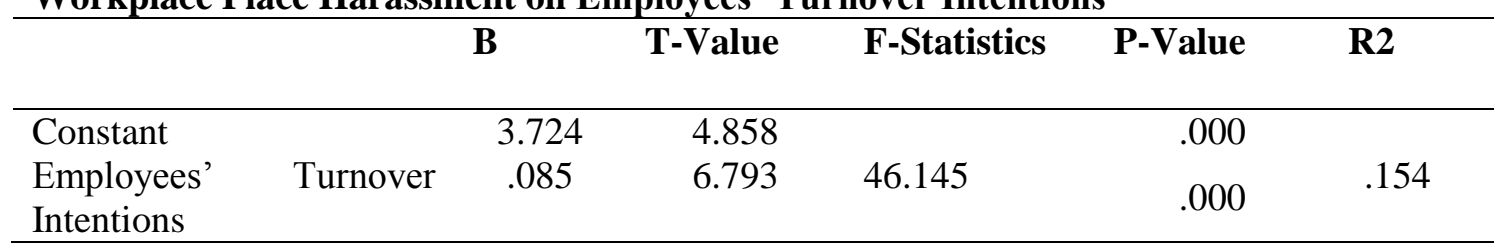

a. Dependent Variable: ETI

b. Predictors: (Constant), HEWPH

According to above three tables findings, in first table model summary of the regression analysis $\mathrm{R}$-value $(\mathrm{r}=.393)$. Which shows the relationship between independents variable the hostile environment and workplace harassment and dependent variable that is the employees turnover intentions, that is positive and moderate in direction and strength $\mathrm{R}$ square value(.154) shows that $15.4 \%$ change in employees turnover intentions is explained by hostile environment and workplace harassment, the value adjusted $\mathrm{R}$ square is (151). The disparityamong $\mathrm{R}$ square and adjusted $\mathrm{R}$ square is 0.3 indicated 
insignificant changes, which thusly disclose to us that the outcomes can be sum up past the example to the populace. The F value (46.145) which is greater than 4 , and shows the overall fitness of the model that the logically model is strong enough and also $p$ Value $=.000$ which is less than significance level that is 0.05 . In Coefficient table $(\beta=.085$, $\mathrm{t}=6.793, \mathrm{p}=.000$ ) which implies that independent variable (hostile environment) have highly significant and low practical effect on dependent variable that is employees turnover intentions. Thus, the first hypothesis is accepted.

Table 5: Regression Analysis to check the effect of Hostile Environment and workplace Place Harassment on Employees' Absenteeism

\section{B $\quad$ T-Value $\quad$ F-Statistics $\quad$ P-Value $\quad$ R2}

\begin{tabular}{lccccc}
\hline Constant & 2.307 & 4.717 & & .000 & \\
Employees' Absenteeism & .068 & 8.617 & 74.260 & .000 & .227 \\
\hline
\end{tabular}

c. Dependent Variable: EA

d. Predictors: (Constant), HEWPH

The interpretations of the tables are about the independent variable that is hostile environment and workplace harassment as a whole and dependent variable that is Employees' absenteeism. In first table the model summary of the regression analysis $\mathrm{R}$ value which is $r=.476$ that shows the positive and moderate relationship between two variables ,the Rsquare value is .227 that highlights the independent variable elucidate $22.7 \%$ dependent variable ,the disparityamong Rsquare and adjusted Rsquare shows that the result can be generalized to whole population.The F value (74.260) which is greater than 4 , and shows the overall fitness of the model that the logically model is strong enough and also $\mathrm{p}$ Value $=.000$ which is less than significance level that is 0.05 . In Coefficient table $(\beta=.068, \mathrm{t}=8.617, \mathrm{p}=.000)$ which implies that independent variable (hostile environment) have highly significant and low practical effect on dependent variable that is Employees absenteeism on the basis of the result the second hypothesis is Accepted.

Table 6: Regression Analysis to check the effect of Hostile Environment and Workplace Place Harassment on Employee's Performance

\begin{tabular}{llllll}
\hline & B & T-Value & F-Statistics & P-Value & R2 \\
\hline Constant & 11.035 & 15.985 & & & \\
Employee's Performance & -.026 & -2.304 & 5.308 & .000 & \\
\hline
\end{tabular}

a. Dependent Variable: EP

b. Predictors: (Constant), HEWPH

The above regression tables are about the independent variable (Hostile environment and workplace harassment) and dependent variable that is Employees performance. In first table that is model summary in which $\mathrm{R}$ value .143 that shows positive but low relationship between two variables, Rsquare value that is .021 shows very minor percent change in dependent variable caused by independent variable. Adjusted Rsquare shows the result can be generalize to whole population. The $\mathrm{F}$ value (5.308) which is greater than 4, and shows the overall fitness of the model that the logically model is just fit and also $\mathrm{p}$ Value $=.022$ which is less than significance level that is 0.05. In Coefficient table $(\beta=-.026, \mathrm{t}=-2.304, \mathrm{p}=.022)$ which implies that 
independent variable (hostile environment) have highly significant and low practical and negative effect on dependent variable that is Employees performance that shows that increase in hostile environment and work-place harassment will decrease in employees performance and therefore the third Hypothesis is also accepted.

\subsection{Discussions}

In light of the study of three hypotheses investigated, the study explored the impact of the hostile environment and workplace harassment on employee absenteeism, employee intentions for employee turnover, and employee performance in different KPK tertiary hospitals. The hostile environment or harassment in the workplace has its impact on the daily work life of employees, especially in this study employee absenteeism, employee turnover intentions due to hostile environment and most important employee performance in KPK hospitals. Employees are often dissatisfied and displeased with the hostile environment and harassment in the workplace that may be different in different workplaces and exactly affect the hostile environment of employees working in different hospitals with different designations. The hostile environment has great effects on the life routine of employees. The hostile environment and workplace harassment have a positive effect on employee turnover intentions in the KPK tertiary hospitals studied.Independent variable (hostile environment) has highly significant and low practical effect on dependent variable that is employees' turnover intentions. Employee turnover is an extremely critical issue for the organization and its reputation because when an employee leaves and organizes the duties and the performance of the rest of the staff is affected(Tag-Eldeen et al., 2017). The hostile environment and harassment in the workplace have a positive effect on absenteeism of staff in different KPK tertiary hospitals.

According to previous findings of the researcher,harassment creates hostile environment and its effects absenteeism employees, intentions of turnover and early retirement(Merkin \& Shah, 2014b). Independent variable (hostile environment) has highly significant and low practical effect on dependent variable that is Employees absenteeism. Hostile environment and workplace harassment have negative impact on employee performance as harassment in the workplace increases, which will have a negative effect on the performance of employees at different levels of operational employees in tertiary hospitals. Deception, antipathy and bitterness clear in various forms such as rude behavior, physical indignation, cursing, imprecation, humiliation, shouting, threats that all of these problems create a hostile environment in the workplace that negatively affect employee performance and force employees to change of intention and absenteeism(Abbas et al., 2017). The environment with different aspects of harassment has strong relation with the different aspects of the employees; in the study, the studied aspect has a positive and negative relation with the type of harassed environment, with an additional dimension that is harassment in the workplace.

\subsection{Conclusions}

The basic role of the study was to access the effect of the hostile environment on different aspects of employees, such as employee absenteeism, employee turnover intentions, and employee performance; three hypothesis inquiries researched in like manner. Subsequently, the accompanying ends came to comparable exact investigations demonstrate that the environment should not be hostile to the organization or workplace; 
as a result, employees will be definitely dissatisfied with different aspects of the routine, such as absenteeism, turnover intentions, and performance. In other cases, disappointment with pay can back off execution, becausestrikes heighten complaints and prompt types of physical or mental withdrawal running from non-appearance and turnover to expanded visits to dispensaries and poor emotional well-being. If the organization cannot control a hostile environment, employees will also definitely go into these kinds of negative situations, which lead to organizational failure. Employees are dissatisfied with the hostile environment, especially absenteeism has increased due to this type of environment and the intentions of employee turnover and performance adversely affect workplace harassment in KPK study hospitals. This, thusly, made their fulfillment low. Hence, this study accepted to be a wake-up chime for hospitals.

There should be serious attention to obtain a better environment for the employees in the study hospitals; especially harassment in the workplace should receive adequate attention from the organization's governing body. This study showed that the hostile environment has a major impact on employee absenteeism, turnover intentions, and performance, leading to poor overall hospital performance. The hostile environment and harassment in the workplace have a negative effect on employee performance as harassment in the workplace increases the negative effect on employee performance at different levels of employee work in hospitals. The environment with different aspects of harassment has strong relation with the different aspects of the employees; in the study, the studied aspect has a positive and negative relation with the type of harassed environment, with an additional dimension that is harassment in the workplace.

\subsection{Recommendations}

The specialists trust that the aftereffects of this exploration have down to earth suggestions for the KPK healing facilities (tertiary hospitals) where the investigation directed. In this way, the Accompanying proposals recognize central indicates that would be valuable the Organization's administration by utilizing its execution evaluation rehearses in accommodating ways. The study identified that the hostile environment has a major impact on absenteeism, employee turnover, and employee performance, which requires the proper attention of hospital management to make their employees more motivated and well oriented. Research experts believe that unless these basic human resource variables handled in a timely manner, they would have an extraordinary potential to avoid and undermine clinic execution objectives and targets by satisfying employees by providing them with a healthy environment.

Based on the study, employees were severely affects by the hostile environment in different aspects, especially absenteeism, turnover intentions and performance. In addition, serious attention from senior management of hospitals to make the environment healthy and strong for employees working at different levels so that the hospital can act at the top of its best levels and environment is more beneficial to employees and hospitals. There should be adequate provisions, checking and balancing the entire hospital environment for general improvement for employees working on different designations. The factor affects and influences more the environment should be priority encounter at all levels with regard to different practices of harassment, if there are reported cases should be treated seriously to thoroughly know the reasons behind and also give the solutions and provide the needs safety at all levels equally. It is also best for top-level management 
to have adequate feedback from low-level employees throughout the hospital for changes and actions in relation to the specific work environment.

\subsection{Future Research Directions}

This study may have practical implications for improving the overall hospital environment, especially the dimensions related to the study. This can make employees more motivated and encouraging to achieve their goals at the individual level as well as the whole and create a healthy environment for the employee. It is best to lead a comparable report in various divisions with various techniques, for example, utilizing a bigger example measure (members) to acquire a real or critical relationship between the hostile environment and absenteeism, employee turnover intentions, and employee performance. It is also better to conduct studies with different moderating and mediating variables that could have more different study variables of results. With different moderating and mediating variables and more dimensions of the independent variables in the study, the results will be definitely more reliable and useful for senior management to make decisions about the environment of a particular workplace.

\section{References}

Abbas, A. A., Abbas, A., Hussein, A., \& Khali, H. H. (2017). The Effect of Hostile Work Environment on Organizational Alienation: The Mediation Role of the Relationship between the Leader and Followers An analytical research study based on the views of a sample of leaders and followers in the general co. for cars m. Asian Social Science, 13(2). https://doi.org/10.5539/ass.v13n2p140.

Atef, G., El Leithy, W., \& Al-Kalyaubi, M. (2017). Factors Affecting Employee's Turnover Intention. Medwell Journal.

Aytac, S., Dursun, S., \& Akalp, G. (2016a). Workplace Violence And Effects On Turnover Intention And Job Commitment: A Pilot Study Among Healthcare Workers İn Turkey. European Scientific Journal, 7881(May), 458-465.

Aytac, S., Dursun, S., \& Akalp, G. (2016b). Workplace Violence And Effects On Turnover Intention And Job Commitment: A Pilot Study Among Healthcare Workers İn Turkey. European Scientific Journal, 1857-7881.

Barakat, M., Tag-eldeen, A., Barakat, M., \& Investigating, H. D. (2018). Investigating the impact of workplace bullying on employees ' morale, performance and turnover intentions in five-star Egyptian hotel operations. https://doi.org/10.21511/tt.1(1).2017.01. Bryant, O. A. (2017). Employee Turnover in the Long-Term Care Industry. Retrieved from http://scholarworks.waldenu.edu/dissertations.

Celik, D. A., \& Oz, E. U. (2011). Social and The effects of emotional dissonance and quality of work life perceptions on absenteeism and turnover intentions among turkish call center employees, 30, 0-4. https://doi.org/10.1016/j.sbspro.2011.10.491.

Cruz, C., Duarte, J., Nelas, P., Antunes, A., \& Almeida, M. (2014). Atención Primaria. Atención Primaria, 46, 107-111. https://doi.org/10.1016/S0212-6567(14)70075-7.

Dieleman, M., \& Harnmeijer, J. W. (2006). Improving health worker performance : in search of promising practices. Human Resources for Health, (September), 77.

Elçi, M., Erdilek, M. K., Alpkan, L., \& Şener, İ. (2014). The Mediating Role of Mobbing on the Relationship between Organizational Silence and Turnover Intention. Procedia Social and Behavioral Sciences. 
Fitzgerald, L. F., Gelfand, M. J., \& Drasgow, F. (1995). Measuring Sexual Harassment: Theoretical and Psychometric Advances. BASIC AND APPLIED SOCIAL PSYCHOLOGY, 17(4), 425-445.

Ismail, M. (2019). Experiences of Egyptian Female Journalists With Workplace Gender Discrimination.

Jung, H. S., \& Yoon, H. H. (2018). How does workplace harassment influence the employees' response in a deluxe hotel?.The Service Industries Journal, 1-24.

Kaare, K. K., \& Otto, T. (2015). Smart health care monitoring technologies to improve employee performance in manufacturing. Procedia Engineering, 100(January), 826-833. https://doi.org/10.1016/j.proeng.2015.01.437.

Lee, M., Kim, H., Shin, D., \& Lee, S. (2016). Reliability and validity of the workplace harassment questionnaire for Korean finance and service workers. Annals of Occupational and Environmental Medicine, 28(1), 1-8. https://doi.org/10.1186/s40557016-0133-0.

Lin, W., Wu, J., Yuan, L., Zhang, S., \& Jing, M. (2015). Workplace Violence and Job Performance among Community Healthcare Workers in China: The Mediator Role of Quality of Life. https://doi.org/10.3390/ijerph121114872.

Maryati Binti Omar, B. (2008). CLIENT SEXUAL HARASSMENT: THE MEASURE AND EFFECTS ON MALAYSIAN PROFESSIONAL WOMEN.

Merkin, R. S., \& Shah, M. (2014a). The impact of sexual harassment on job satisfaction, turnover intentions, and absenteeism: findings from Pakistan compared to the United States. SpringerPlus. https://doi.org/10.1186/2193-1801-3-215.

Osman, S., Shariff, S. H., \& Lajin, M. N. A. (2016). Does Innovation Contribute to Employee Performance? Procedia - Social and Behavioral Sciences. https://doi.org/10.1016/j.sbspro.2016.05.036.

Tag-Eldeen, A., Barakat, M., \& Dar, H. (2017). Investigating the impact of workplace bullying on employees' morale, performance and turnover intentions in five-star Egyptian hotel operations. Tourism and Travelling, 1(1), 4-14. https://doi.org/10.21511/tt.1(1).2017.01.

Ugwa, E. A., Muhammad, L. M., \& Ugwa, C. C. (2014). Job Satisfaction among Nurses and Doctors in a Tertiary Hospital in A Cross- Sectional Study. International Journal of Hospital Research, 3(1), 11-18.

Walker, S. Y. (2018). Workplace issues: Am I in a hostile work environment?.Teaching and Learning in Nursing, 13(2), 95-96.

Wang, Q., Bowling, N. A., Tian, Q. T., Alarcon, G. M., \& Kwan, H. K. (2018).Workplace harassment intensity and revenge: Mediation and moderation effects.Journal of Business Ethics, 151(1), 213-234.

Webber, F. (2019). On the creation of the UK's 'hostile environment'.Race \& Class, 0306396819825788 . 